\title{
RECONFIGURABLE OPTICAL ADD AND DROP MULTIPLEXERS A REVIEW
}

\author{
Devendra Kr.Tripathi, Pallavi Singh, N.K.Shukla and H.K.Dixit \\ Dept. of Electronics\& Communication, University of Allahabad, Allahabad, \\ India
}

\begin{abstract}
Optical multiplexing is the key function of a WDM network and reliable method for data transport networks. WDM networks configured as rings/mesh along with Optical Add-Drop Multiplexers supports added flexibility, simplicity and augment the spectral efficiency. Further enhancement achieved with Reconfigurable OADM architectures, growing briskly along with automatic network management, let the transport network to acclimatize with dynamically varying environment and flexibly respond to the transport network changes. It permits single or many wavelengths to be added and/or dropped from a transport fiber without optical-to-electrical-to-optical domain translation. Presently ROADM technology has revolutionized optical networking and an inseparable part of modern optical communication offering huge bandwidth for data transport at minimum expense. In this view the article presents comprehensive study for numerous generations of ROADM and their architecture and persistent development.
\end{abstract}

\section{KEYWORDS}

Thin-film filters (TFFs), optical transport network (OTN), fully-reconfigurable OADM (FROADMS)

\section{INTRODUCTION}

Efforts to efficiently utilize the valuable communication resource various schemes have been developed in the past to support numerous users within the same transmission medium. This notion is referred as "multiplexing", performed by exploiting orthogonality in various physical dimensions. Thus number of techniques optical code division multiplexing access(OCDMA),optical orthogonal frequency division multiplexing(OOFDM), polarization division multiplexing(PDM), Optical time division multiplexing (OTDM) the next generation transmission optical to optical scheme permits to surmount the signaling rate limits forced by electronics and wavelength division multiplexing(WDM) devised to augment spectral efficiency. Although WDM optical networks illustrated the short term answer for the steady raise in bandwidth requirement. WDM networks exploit the enormous fiber bandwidth and transmit several logical connections on the similar fiber [1]. Present growth in Dense Wavelength Division Multiplex systems has made achievable transmission with hundreds of channels presenting total capacities in surplus of Terabits/sec. Later on transmission with dense WDM (DWDM) channels were put into practice as the competent exercise of fiber bandwidth, as economical and trustworthy mechanism for shipping information bits in long haul in addition to the local metro networks. However the conventional way by means of DWDM repeaters on the transmitting and receiving channels were restricted, due to expenditure and systems complexity. So the competent 
exercise of fiber bandwidth was to exploit the costly network resource, for that numerous alternatives have been attempted in conjunction with DWDM. Amongst Optical Add-Drop Multiplexers (OADM) was one of the intelligent techniques for the handling of communications signals. Add and drop multiplexer is the fundamental constructional block of fiber-optic communication network constructions. It employs either unidirectional or bidirectional traffic arrangements. The OADM selectively removes or adds wavelength from a multiplicity of wavelengths in a fiber, and thus form traffic on the particular channel. It then adds in the same direction of data flow the same wavelength, but with different data content [2]. A simpler OADM which can be generally employed to add and drop wavelengths has been exhibited in the Fig.1, depending upon the way of add/drop it can be classified in differently. Key types were fixed OADM (FOADM), were dedicated for specific DWDM channels, and the dynamic/Reconfigurable (ROADM) which can alter the selected channel routing to the optical networks. However the FOADM requires optical-to-electrical and electrical-to-optical alterations as well as required manual adjustments at EDFA because of channels being dropped or added. Normally FOADM were built with thin-film filters (TFFs), along with stationary nature of the arrangement as well as the requirement of manual changes so the operational cost were too high for FOADMs, and were two major shortcomings [2-3].

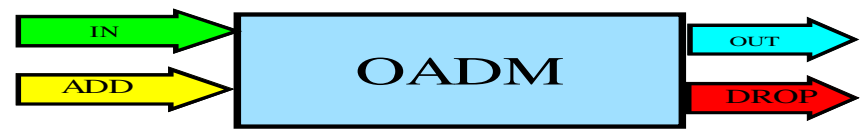

Figure1. Basic Add / Drop Multiplexer

Now to handle with dynamically varying traffic needs the scheme reconfigurable OADM (ROADM) were devised, which can alter the selected channel routing to the optical networks. It reduces need for optical-to-electrical-to-optical (O-E-O) translations. An optical transport network (OTN) containing ROADM nodes with different add/drop capabilities depicts numerous flexibilities for the set up of light paths, reconfigurability. Such capabilities permit network operators rapidly and flexibly act in response to network alterations. Reconfigurability in the network does not need rescheduling for the carriers, and the light paths were set up or broken down at once at any time. ROADMs do not add/drop the same wavelengths permanently and they remotely organize to add/drop different wavelengths at different times. As well as there were no need of high-speed electronic switching gear and thus minimizes capital expenses requirements although due to electrical signal processing it loses the capacity little bit[4].ROADM has been observed with numerous properties such as Colorless, Directionless, and Contention less. In the Colorless, every add/drop port of an ROADM node should not be wavelength selective and the architectures with Colorless permit any wavelength on an express fiber to be connected to any add/drop transponder linked with that optical fiber.

The Directionless indicates that add/drop port at a node is not nodal degree selective. Here any channel could be added on any port and can be directed to any other outbound nodal degree, and vice versa. The directionless ROADMs were that in which the contention limitation were eliminated, under the limit it is called contention less nodes. An ROADM with Colorless and Directionless broadens notion to sharing a single group of transponders in between all wavelengths from all express fiber directions. The contention factor is the maximum number of the add/drop nodes. The add/drop contention in the network nodes is a source of light path blocking, that adds extra constraints to the optical network planning and deteriorates the 
networks capacity. The Contention less denotes that within the ROADM node, the setup of crossconnects between add/drop ports and outbound/inbound nodal degrees do not stop other crossconnects from being set up; provided a free add/drop port is there and a free wavelength on an outbound/inbound degree, a cross-connect can always be set up within the node[5].

Rigorous studies around mid 2000s such as two degree ROADM using PLC (planar light wave circuit) switches were exercised, followed by N-degree ROADM employing wavelength selective switch. Growth of PLC switches permitted the exercise of ring topologies and WSS switches to interconnect rings and mesh topologies were presented[6].Next version of OXC employing fiber uses regular AWG MUX/DEMUX were presented, wavelength contention resulting structural design employing WSS(1: N) illustrated to join degrees to the A/D arrangement[7-8].The blocking probability in FOADM system were evaluated and compared with flexible ROADM counterpart, later investigated for the limited tunability in LROADM, can add/drop from only a subset of adjoining wavelengths and low cost in contrast to fully-reconfigurable OADM (FROADMS)[9-10].Afterward investigated for the non-Poisson traffic model, the model calculates that traffic peakedness presented a significant part in calculating the blocking performance[11].In this sight the article presents a brief very recent literature review. In the next section brief theory of ROADM and its concise summary followed by conclusions have been discussed.

\section{THEORETICAL PRESENTMENT OF ROADM}

ROADM permits remote configuration, reconfiguration, automatic power balancing and with initial deployment of a system the planning of whole bandwidth task need not be carried out. Initially ROADM viability appeared with long-haul DWDM equipment although by 2005 , it comes into view for metro services to deal along with the traffic driven by the growing need for packet-based services. The ROADMs reconfiguration functions are achieved using various switching technologies including liquid crystal, thermo optic, micro electromechanical systems (MEMS)and tunable optical filter technology[12].ROADM were implemented in many ways such as Fixed point ROADM. It is similar to fixed point OADMs though and has tunable filters. Fixed point ROADMs employ wavelength blocker (WB) devices with high insertion loss and integrated photonic light wave circuit (PLC). Wavelength selective ROADMs use flexible filters, wavelength selective switches (WSS) and optical cross-connects. Study illustrated that ROADM are a significant network element in the next generation all optical networks for the applications in both long-haul and metro systems. It further enhances the communication networks efficiency as well as dynamic connectivity in the optical networks with added network survivability. It uses field-proven technology and components, contributing a reliable and low cost solution due to switching [13].

ROADM networks are accompanied with fundamental components as Amplifiers (Pre-Amp \& Post-Amp), Dispersion Compensation unit, Transponders, Optical Service Channel, Optical Power supervising and ROADM Subsystem. Basically ROADM can be classified as of different types as Wavelength Selective Switches (WSS), Optical Cross-Connects (OXC), in the broadest sense as Type I/II ROADM and Multidegree-ROADM. 


\section{Wavelength Selective Switches (WSS)-}

Wavelength Selective Switches (WSS) are the heart of the ROADM.WSS realizations employs free-space optics and any wavelength, group, or band of wavelengths can be directed to any output fiber. WSS's are characteristically a single bulk diffraction grating, is shared for all the demultiplexing and multiplexing.WSS permits any number of channels to exit any port. The output patterns can be changed or reassigned to several output fibers through electrical interface. Here $\mathrm{n} 1 \times \mathrm{N}$ switches are needed for a $1 \times \mathrm{N}$ WSS with $\mathrm{n}$ channels. For degree-N connectivity in a ring-to-ring interconnect a $1 \times \mathrm{N}$ WSS can be used either, adding/dropping channels as a ROADM with one Express port and N-1 Drop the ports[14].To vary the fiber connectivity between the transceiver and networks access ports for a given direction and colorless, directionless realizations extra WSS's were deployed [15].

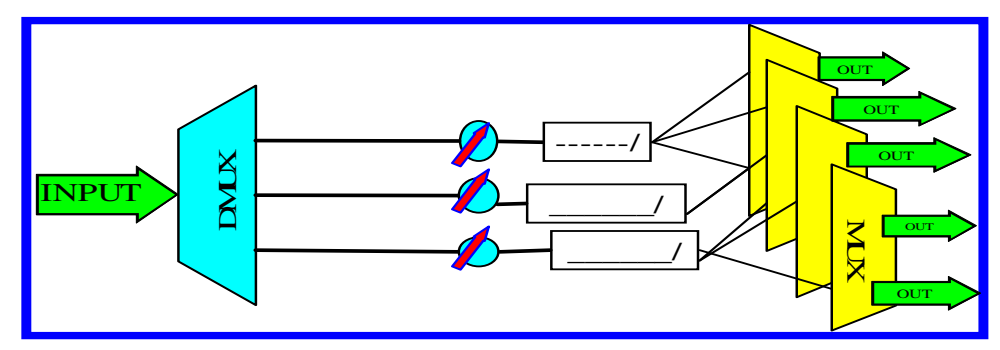

Figure2. Basic Wavelength Selective Switch
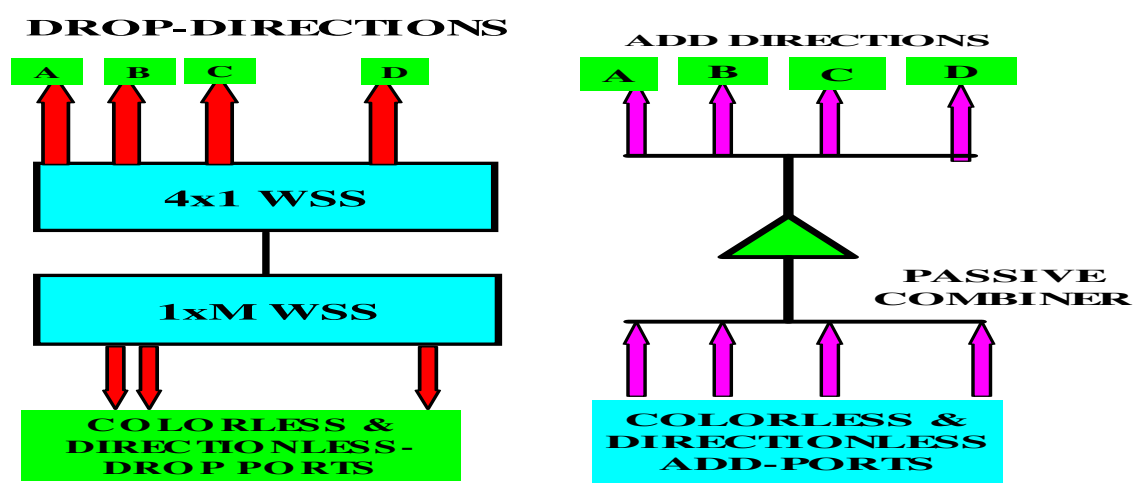

Figure 3. Colorless and directionless access ports for ROADM of degree

\section{Optical Cross-Connect-}

Optical Cross-Connects (OXC) is one of the key network elements in the optical layer. These are large switches employed to dynamically service as well as network restoration and enables reconfigurable optical networks. OXC is employed for wavelength cross-connect switching and important for the mesh networks. Through an increased number of connections and a higher level of redundancy the mesh topology presents higher network capacity, efficiency, and reliability. However increased hardware expenditure is a major barrier to the deployment of the mesh networks. The OXC at every node in the transparent sub-networks are with polymer-on-silicon 
PLC platform which delivers low cost, small size, high optical performance, low electrical power consumption, high yield, high throughput, short cycle time, and fast time to market [16].

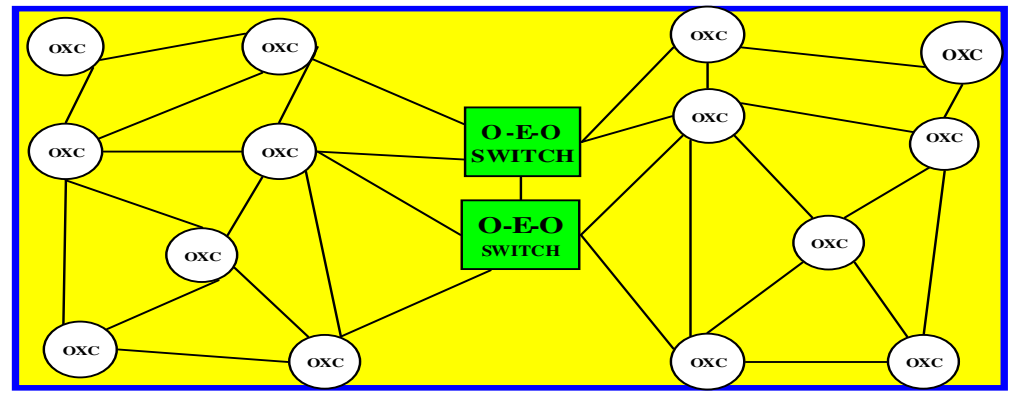

Figure 4.ROADM Mesh Network with OXC as two interconnected islands

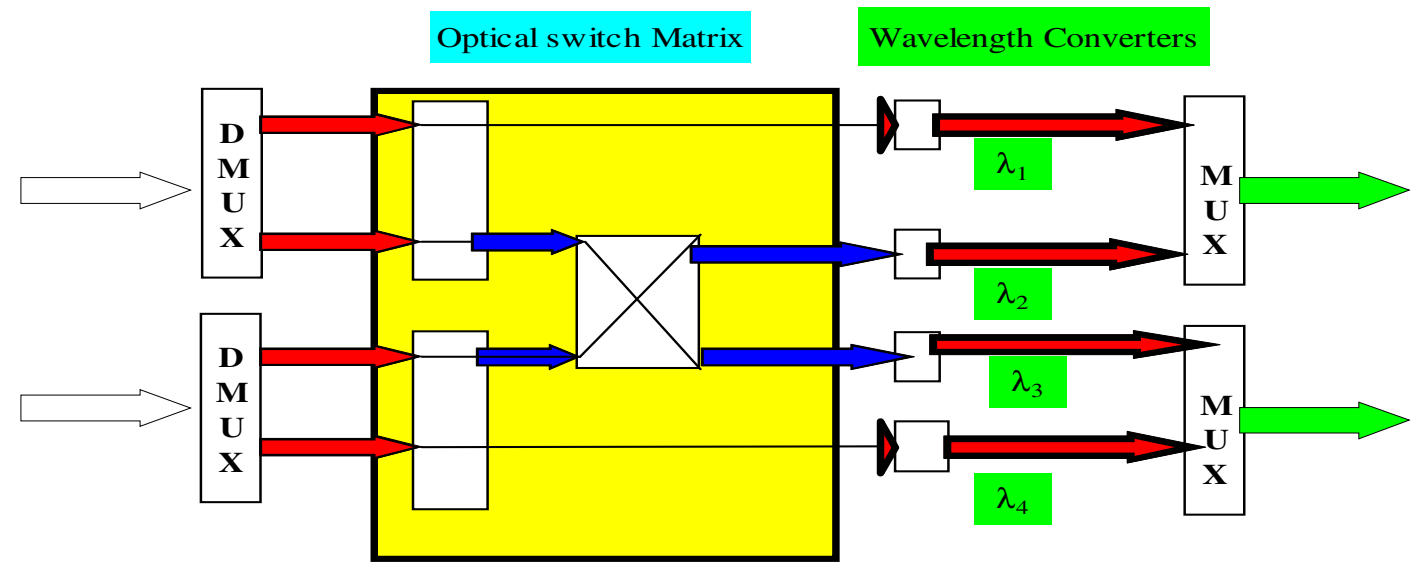

Figure5. OXC $(4 \times 4)$ architecture using wavelength converters

Two input fibers as illustrated in the fig. 5 were each carrying two wavelengths. Either wavelength can be switched to any of the four output ports. The OXC consists of three $2 \times 2$ switch elements. Wavelength converters prevent cross-connected light waves from contending for the same output fiber.OXC provides numerous key functions as service provisioning i.e. provision of light paths in a large network in an automatic manner, ability to switch signals with arbitrary bit rates and frame formats, protection (protects light paths against fiber cuts and equipment failures in the network), and performance monitored test access and fault localization in large networks.

\section{The Reconfigurable OADM of Type- I}

\section{The First Generation Type-I ROADM}

It is the most elementary type of ROADM with fixed (colored) ports relies on the silica-on-silicon arrayed (SSA) referred to as Type-I, costs less. Individually packaged chips were spliced all together, namely SSA-waveguide grating (AWG) chips and polymer-on-silicon chips comprised of switches. Demultiplexing/multiplexing, add/drop switching, and optical power monitoring/load balancing is performed with SSA-based type- I- ROADM. It comprised of three AWG's of thirty two channels and two switches of sixteen channels, thus in total of five packages. Thirty two 
channels $(\mathrm{N})$ in totality, on the both sides of a PCB complete package are mounted, along with control electronics [16-19].

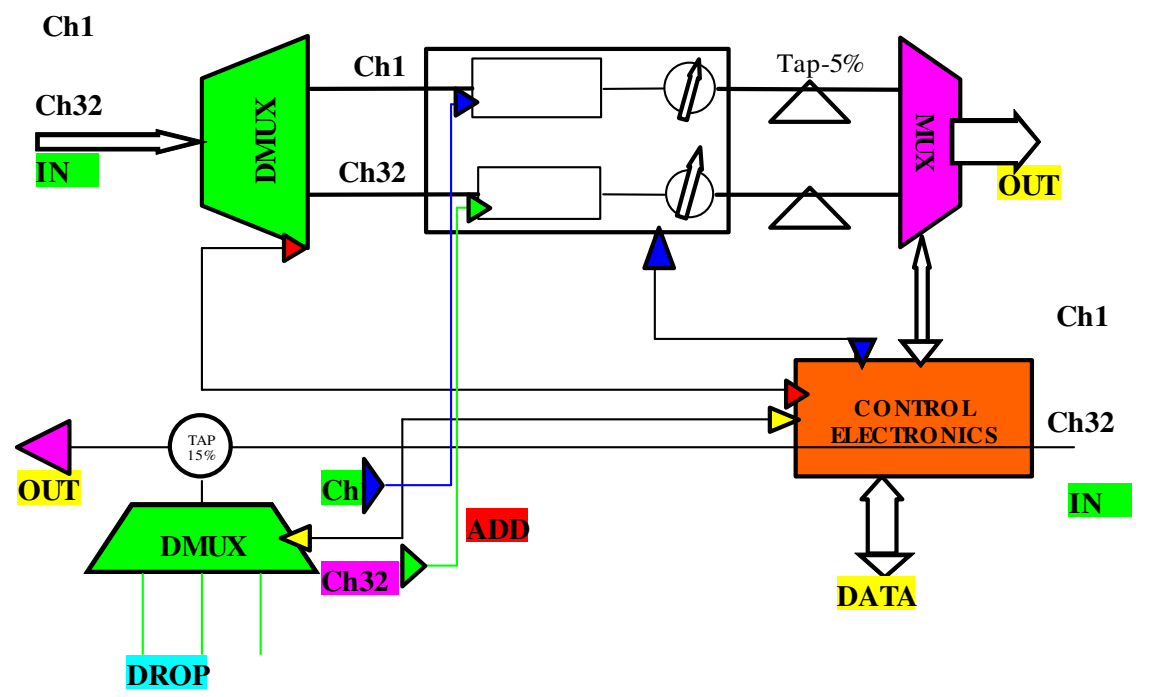

Figure 6. SSA-based Gen 1 Type I ROADM

\section{The Second -Generation Type-I Reconfigurable OADM}

The Reconfigurable OADM of second generation are also based on silica-on-silicon arrayed (SSA) and implementation is through chip-to-chip connection along with additional integration, well referred to as the Second Generation Type I ROADM. Together with numerous benefits, it diminishes excess loss by replacing two fiber array pigtails with a single chip-to-chip coupling, the space needed for fiber ribbons, splices were removed ,removal of fiber arrays amid chips and a sub-assembly of hybrid ROADM, thus number channels are increased thus resulting in less expenditure[20].

\section{Type II Reconfigurable OADM}

These types of networks offer colorless Add/Drop ports, and are based on the wavelength blocker (WB), SSA approaches and may be further classified into number of generations.

\section{First -Generation Type-II Reconfigurable OADM}

This type of Reconfigurable OADM are mostly applied for the long-haul networks along with $50 \mathrm{GHz}$ interchannel spacing and these type of Reconfigurable OADM are based on free-space optics that utilizes MEMS or LCD actuation. These are based on the generation-1 WB and SSA schemes, the WB-based systems are also referred to as 'Broadcast and Select' architecture. Together with use of tunable filters at the Drop ports and tunable lasers at the Add ports the ports, are made colorless without having impact on the path [19]. 


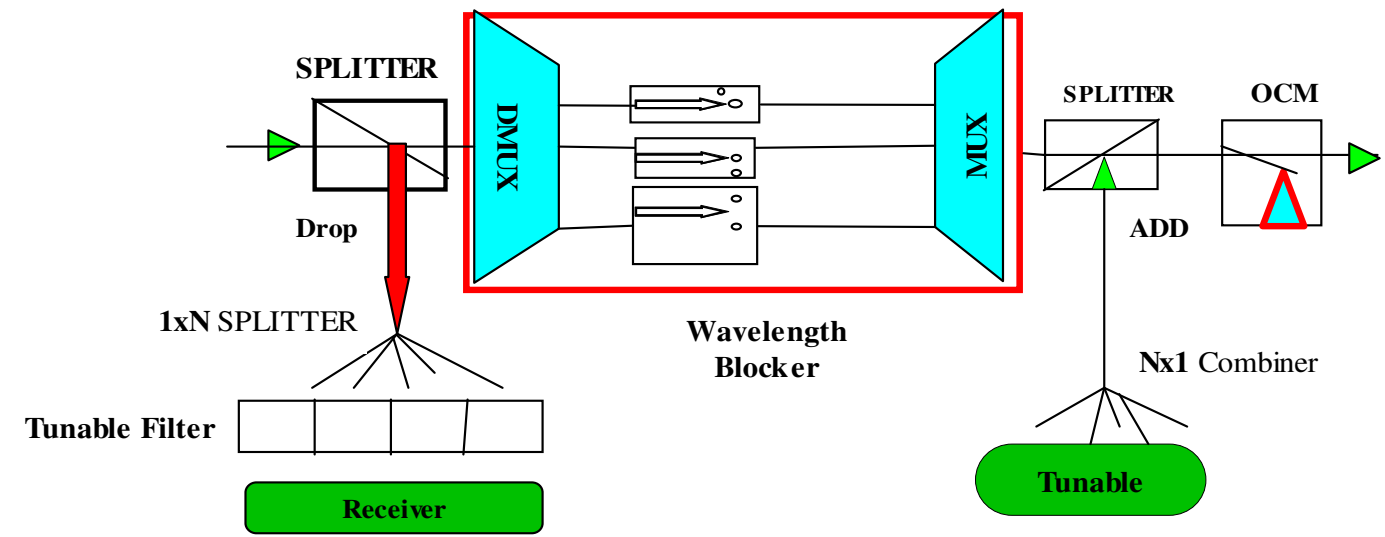

Figure 7. (a) Gen 1 Type II ROADM -Wavelength blocker based broadcast and select Architecture

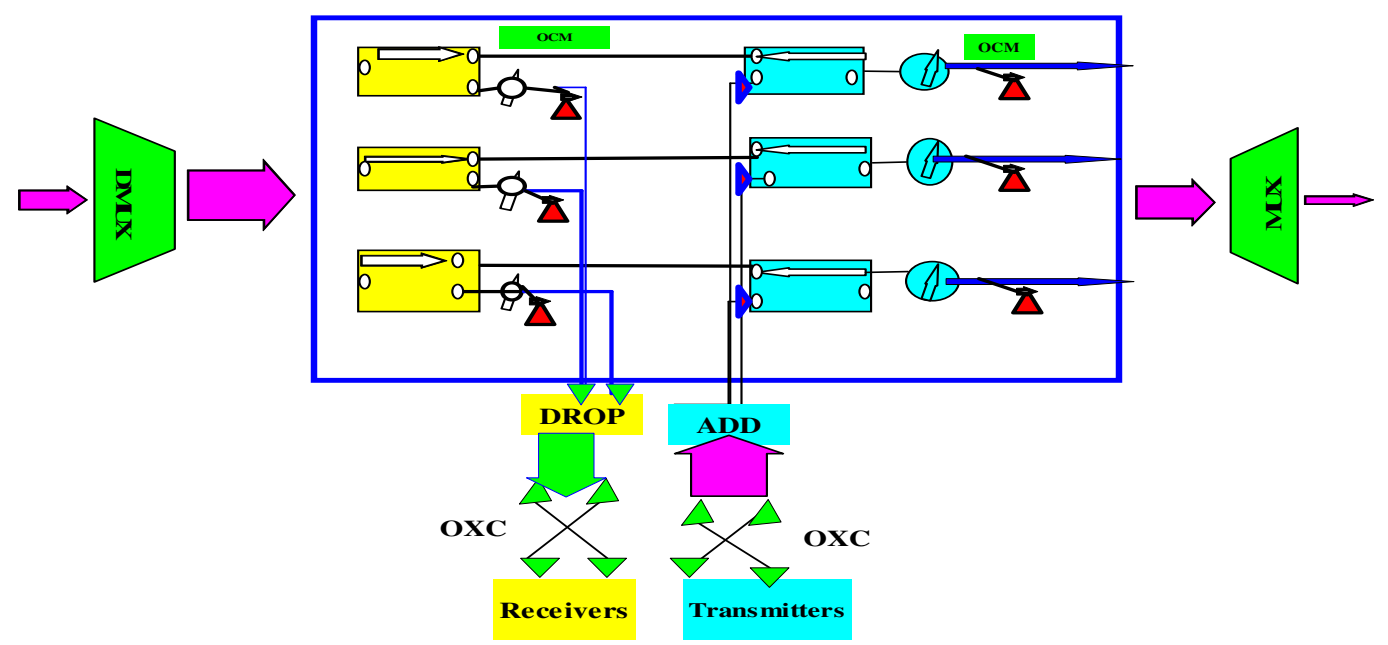

Figure 8. (a) Gen-1 Type- II ROADM -PLC based-SSA approach Architecture

\section{The Second-Generation Type-II Reconfigurable OADM}

These types of architectures comprised of colorless Add and the Drop ports, cross-bar switches for adding/dropping individual channels, optical power taps, integrated photodiodes for power monitoring and channel power equalization. The Gen-2 SSA-based Type-II ROADM employ polymer-on-silicon single-chip integrated channel switching/monitoring/equalizing/shuffling photonic path for West/ East fiber pair[21].Although a self-balanced wavelength-supple ROADM performance was actualized when this module is placed in between two silica-on-silicon AWG Demux/Mux pairs.

\section{Third-Generation Reconfigurable OADM}

These are further enhanced version of ROADM architectures along with Polymer-on-silicon integrated channels monitoring/ switching/equalizing chip along with polymer-on-silicon matrix 
switches, silica-on-silicon AWG chips and with East/West fiber pair, was referred to as Generation 3- SSA-based Type-III ROADM having more competent.

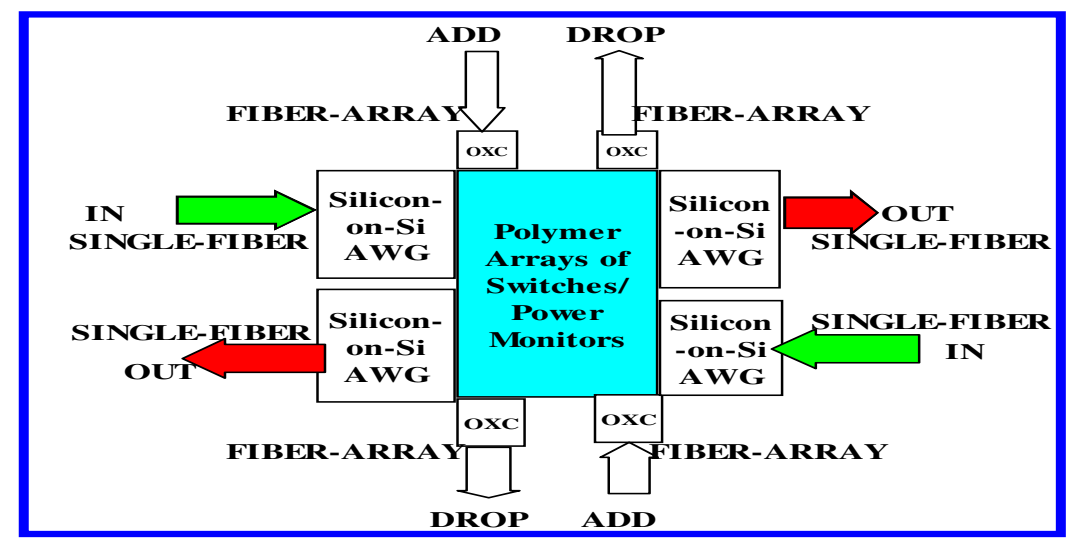

Figure9. The Self balanced Generation-3 Type-II- ROADM

\section{Multi-Degree ROADM}

These are also an enhanced version of the ROADM's where the degree of ROADM refers to the number of bidirectional multi wavelength interfaces the device supports. Two DWDM trunk directions facing East and West generally deployed with ring/linear networks are referred to as 2degree ROADM. Generally a given direction is with a pair of fiber for transmit /receive DWDM line signal .The fiber pair which serves as given direction is referred to as a degree. The employed ROADMs with higher than two degrees were usually called as multi-degree. Generally N-degree ROADM were designed employing N Nx1 WSSs and with every WSS operates as a specified degree, while extra WSSs can be deployed to implement the colorless access ports. ROADM have numerous connectivity capacities and Connectivity depicts how many optical links a particular ROADM may carry. Based on the degree ROADM were classified as degree-2 ROADMs or multiple-degree ROADMs, Two/higher degree ROADMs were employed in ring/mesh networks and thus diminishes the expenditure, viable option deployed for the next generation optical network architectures depending on ROADMs [22-24]. 
Electrical \& Computer Engineering: An International Journal (ECIJ) Volume 3, Number 1, March 2014

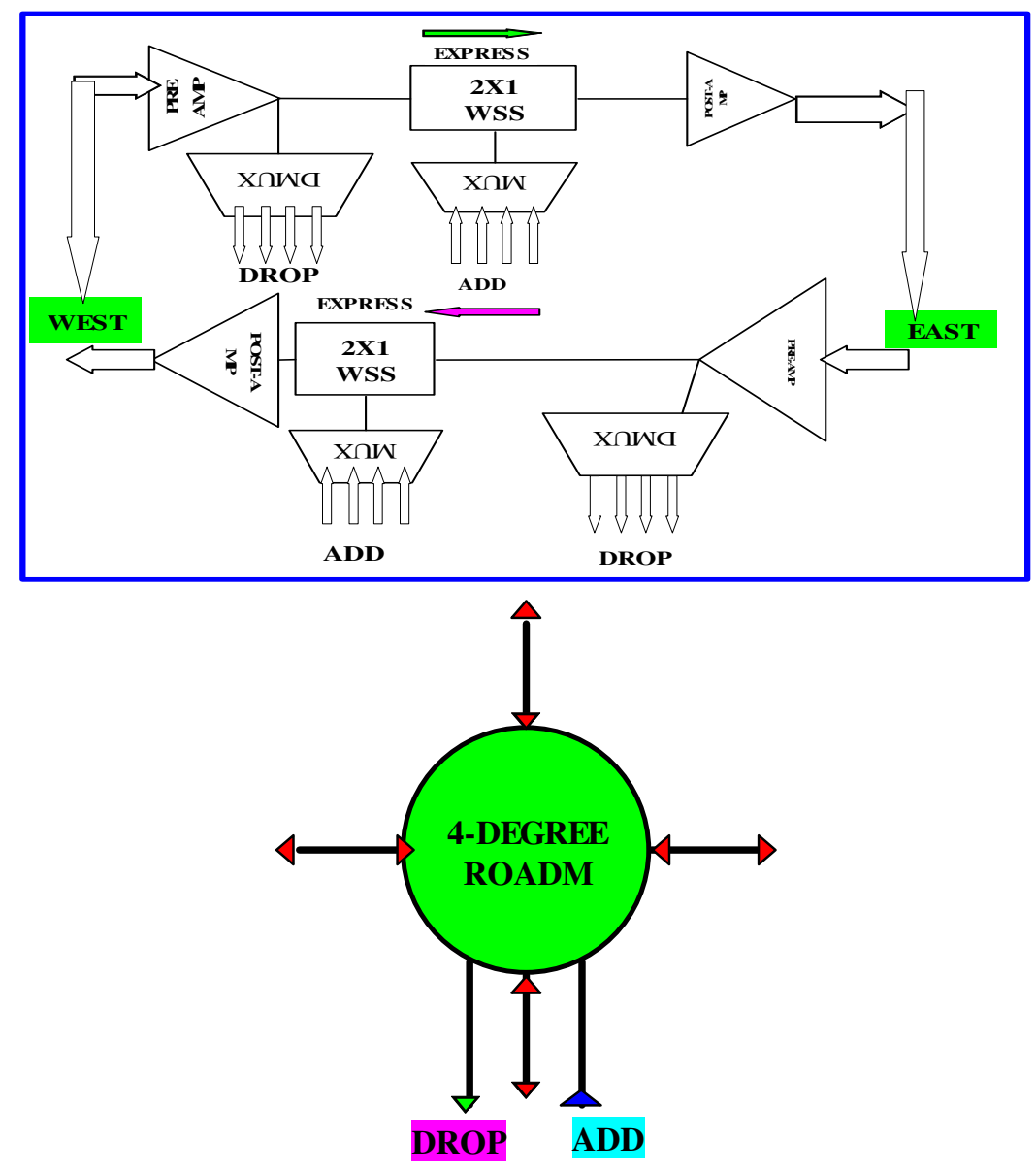

Figure10. A Full 2 degree ROADM AND 4-degree ROADM

\section{SUMMARY-Basic ROADM Types}

Basically for degree $\mathrm{N}$ node $\mathrm{N}$ fibers, wavelengths per fiber for $\mathrm{NxN}$ switches are required. For drop operation tunable filters are used, $\mathrm{NxM} \& \mathrm{MxN}$ at $\mathrm{A} / \mathrm{D}$ give full reconfigurability [19].As illustrated in the table 1 and 2 which illustrates a concise summary of the different types of ROADM architectures along with their respective pros and cons. 
Electrical \& Computer Engineering: An International Journal (ECIJ) Volume 3, Number 1, March 2014

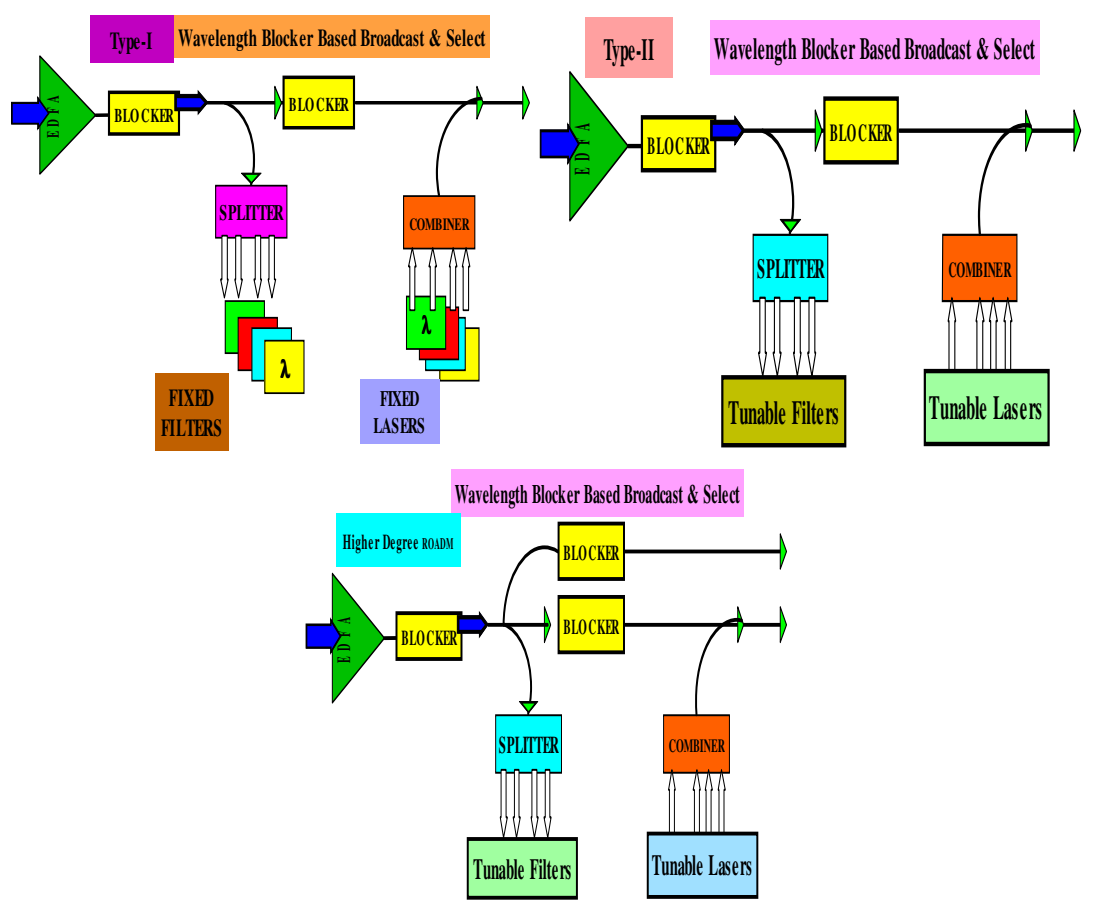

Figure11. Wavelength blocker based broad cast and select ROADM Type's

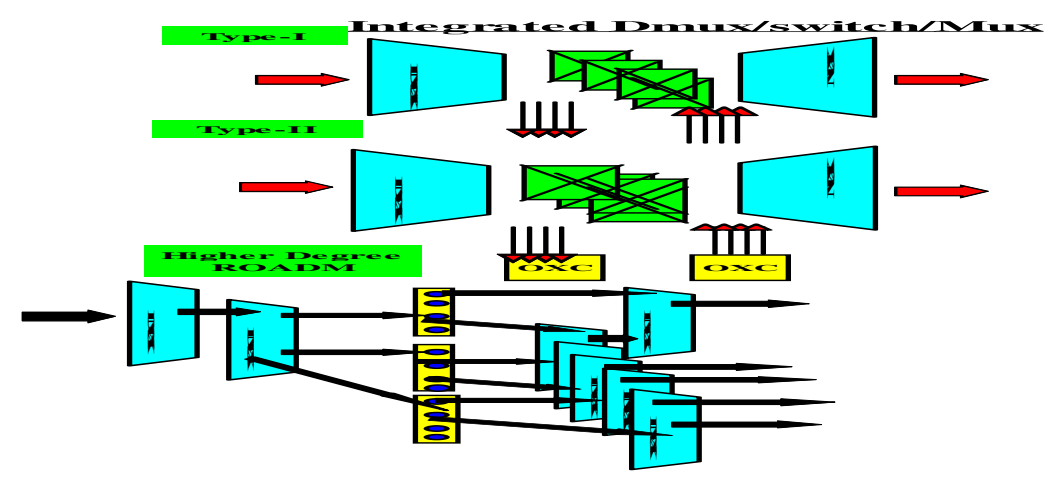

Figure12. Integrated DMux/Switch/Mux ROADM 
Electrical \& Computer Engineering: An International Journal (ECIJ) Volume 3, Number 1, March 2014

Table1.Types of ROADM's and characteristics

\begin{tabular}{|l|l|l|l|l|}
\hline $\begin{array}{l}\text { TYPES } \\
\text { ROADM }\end{array}$ & $\begin{array}{l}\text { Type I } \\
\text { ROADM }\end{array}$ & $\begin{array}{l}\text { Type II } \\
\text { ROADM }\end{array}$ & $\begin{array}{l}\text { Wavelength Selective Switch } \\
\text { (WSS) }\end{array}$ & $\begin{array}{l}\text { Optical Cross-Connect } \\
\text { (OXC) }\end{array}$ \\
\hline Colorless & NO & Yes & Yes & Yes \\
\hline $\begin{array}{l}\text { Add/Drop } \\
\text { Channels }\end{array}$ & $\mathrm{N}$ & $\mathrm{M}$ & M-1 & $\begin{array}{l}\text { N/A-(Mesh Connectivity } \\
\text { only) }\end{array}$ \\
\hline $\begin{array}{l}\text { Multiple- } \lambda \text { 's-per- } \\
\text { Port }\end{array}$ & NO & NO & Yes & Yes \\
\hline $\begin{array}{l}\text { Subsystems per } \\
\text { Node }\end{array}$ & $\begin{array}{l}\text { S- } \\
\text { Subsystem degree } \\
\text { 2Node }\end{array}$ & $\begin{array}{l}\text { Subsystems } \\
\text { per Degree 2 } \\
\text { Node }\end{array}$ & $\begin{array}{l}\text { N-Subsystems per } \\
\text { Degree N-Node }\end{array}$ & $\begin{array}{l}\text { 1-Subsystems per } \\
\text { Degree N-Node }\end{array}$ \\
\hline Node Degree & $\begin{array}{l}2 \\
\text { 2 }\end{array}$ & N & N \\
\hline
\end{tabular}

Table2.Advantages \& disadvantages of the ROADM's

\begin{tabular}{|c|c|c|c|c|}
\hline ROADME & SSA & WSS & WB & OXC \\
\hline Advantages & $\begin{array}{l}\text { Small cost } \\
\text { little size } \\
\text { Simple software } \\
\text { \& hardware } \\
\text { \#A/D port }=\mathrm{N} \\
\text { (all } \lambda \text { 's) }\end{array}$ & $\begin{array}{l}\text { Any multiple } \lambda^{\prime} \text { 's to any } \\
\text { port } \\
\text { Degree upgradeable }\end{array}$ & $\begin{array}{l}\text { Initially to be } \\
\text { ready } \\
=A D \text { port }=N \\
\text { (all } \lambda \text { 's) }\end{array}$ & $\begin{array}{l}\text { Any multiple } \lambda \text { 's from any port to any } \\
\text { port Degree upgradeable, } \lambda \text { up gradeable } \\
\text { Simple so ftware \& hardware } \\
\text { Small size }\end{array}$ \\
\hline Disadvantages & $\begin{array}{l}\text { Fixed } \lambda \text { port } \\
\text { Not degree } \\
\text { upgradeable }\end{array}$ & $\begin{array}{l}\text { Expensive, extra \$ for } \\
\text { 'Add' Complex } 5 \text { oftware } \\
\text { \& hardware } \\
\text { \#A D ports } \mathrm{M}<\mathrm{N} \text {, not } \\
\text { hupgradeable } \\
\text { Large size }\end{array}$ & $\begin{array}{l}\text { Large size } \\
\text { ExpensiveFixed } \\
\lambda \text { port } \\
\text { Not degree } \\
\text { upgradeable }\end{array}$ & Next generation for few carriers \\
\hline
\end{tabular}

\section{CONCLUSION}

The article has presented a comprehensive study of the ROADM architectures, it avoids O-E-O translations thus eliminates requirement of the costly high-speed switching electronics. Owing to all optical transmission it has great potential than their electronic counterparts. ROADM enabled service providers of Generation first and the second remotely add/ drop and redirect wavelengths across the optical network. However shortcoming were in terms to offer a straightforward and flexible answer for optical branching, one of the significant capability for the service providers providing triple play services.Generation-3 ROADM are SSA-based, Polymer-on-silicon integrated channels monitoring with matrix switches, fiber pair(East/West), higher degree ROADM diminishes the expenditure with enhanced capability. Development of the future generation ROADM architecture relies on the growth of supporting optical components maturity, progress of integrated optics technology, upgrade capability of the equipment and novel algorithms that will be add to development of the advanced ROADMs design. It is to be developed around the future broadband communication network service needs, along with considerable decrease in the operational costs, effective interoperability and the flawless service evolution. 
Electrical \& Computer Engineering: An International Journal (ECIJ) Volume 3, Number 1, March 2014

\section{REFERENCES}

[1] A.D. Ellis, et.al. "Full 10x10 Gbit/s OTDM data generation and demultiplexing using electro absorption modulators", Elect Lett, vol. 34, no.18, p. 1766, (1998).

[2] J. Ip, .Demultiplexer for next generation DWDM network., OSA Trends in Optics and Photonics Vol. 29, WDMComponents, Daniel A. Nolan, ed. (Optical Society of America, DC) pp. 34-41, 1999.

[3] Advanced optical Components at the add/drop node. Light wave August, 1999,http://www.lightwaveonline.com/articles/print/volume-16/issue-9/special-report/.

[4] J. M. Tang and K. A. Shore, "Wavelength-routing capability of reconfigurable optical add/drop multiplexers in dynamic optical networks,"J. Lightw. Technol., vol. 24, no. 11, pp. 4296-4303, Nov. 2006.

[5] R. Jensen, "Optical switch architectures for emerging colorless/directionless/contentionless ROADM networks," in OFC/NFOEC, 2011.

[6] R. Jensen, "Optical switch architectures for emerging colorless/directionless/contentionless ROADM networks", in Optical Fiber Communication Conference. Optical Society of America, 2011, p.OThR3.

[7] M. D. Feuer et al., "Intra-node contention in dynamic photonic networks", J. Lightwave Technol., vol. 29, no. 4,pp. 529-535, Feb 2011.

[8] P. Pavon-Marino and M. Bueno-Delgado, "Distributed online RWA considering add/drop contention in the nodes for directionless and colorless ROADMs", in National Fiber Optic Engineers Conference, Optical Society of America, 2012, paper NW3F.4.

[9] J. Wagener et al "Characterization of the economic impact of stranded bandwidth in fixed OADM relative to ROADM networks," presented at the Optical Fibre Communication Conf./National Fiber Optic Engineers Conf. (OFC/NFOEC), Anaheim, CA, Mar. 5-10, 2006, Paper OThM6.

[10] T. Hsieh et al "Banding in optical add-drop multiplexers in WDM networks: preserving agility while minimizing cost," in Proc. IEEE Int.Conf. Commun., 2003, vol. 2, pp. 1397-1401.

[11] S. Subramaniam et al "The benefits of wavelength conversion in WDM networks with non-Poisson traffic," IEEE Commun. Lett., vol. 3, no. 3,pp. 81-83, Mar. 1999.

[12] Light Reading's Heavy Reading - "ROADMs and the Future of Metro Optical Networks", May 2005, HEAVY READING, VOL. 3, NO. 8, MAY 2005, ROADMS and the future of metro optical networks, $1-5$

[13] David Wang ; Yan Bin Shao, "Reconfigurable optical add/drop multiplexers (ROADM): a key network element for all optical network"SPIE Proceedings I Volume 4907.proc. SPIE 4907, Optical Switching and Optical Interconnection II, 16 (September 2, 2002); doi:10.1117/12.482289.

[14] B. P. Keyworth, "ROADM Subsystems \& Technologies," Proc. OFC/NFOEC (2005).

[15] Steven Gringeri et al., "Flexible Architectures for Optical Transport Nodes and Networks," IEEE Commun.Mag., July 2010.

[16] L. Eldada, "Organic photonics," chapter in Microphotonics: Hardware for the Information Age, Ed. L. Kimerling,MIT, Cambridge (2005).

[17] L. Eldada, "Photonic integrated circuits," in Encyclopedia of Optical Engineering, Ed. R. Driggers,Marcel Dekker, NewYork (2003).

[18] L. Eldada et al., "Hybrid Organic-Inorganic Optoelectronic Subsystems on a Chip," Proc. SPIE 5729, 200 (2005).

[19] Louay Eldada,'Advances in Optoelectronic Technologies for ROADM Subsystems, DuPont Photonics Technology,http://www.wocc.org/wocc2005/cover/Slides/S9/S9\%20Louay\%20Eldada.pdf.

[20] A. M. Radojevic et al., "Hybrid-integrated ROADM for reconfigurable optical networks," Proc. ECOC 30, Tu1.4.5 (2004).

[21] L. Eldada et al. "Fully reconfigurable optical add/drop multiplexing subsystem on a chip," Proc. SPIE 5279,241 (2003).

[22] J. M. Tang and K. A. Shore, "Wavelength-routing capability of reconfigurable optical add/drop multiplexers in dynamic optical networks,"J. Lightw. Technol., vol. 24, no. 11, pp. 4296-4303, Nov. 2006. 
[23] M. Mezhoudi et al., "The value of multiple degree ROADMs on metropolitan network economics," in Proc. OFC, Mar. 2006, pp. 1-8.

[24] K. Grobe, "Applications of ROADMs and control planes in metro and regional networks," in Proc. OFC, Mar. 2007, pp. 1-12.

\section{Authors}

D. K. Tripathi received his B.Sc (A.U), B. Tech and M. Tech degree in Electronics and Telecommunication engineering from the Department of Electronic \& Communication, University of Allahabad. Presently he is pursuing his Ph.D. degree in electronics engineering. His area of interest includes Wireless communication technology and fiber optics communication. He is life member of ISTE.

Pallavi Singh received B.Tech and M.Tech degrees in electronics and Telecommunication engineering from Department of Electronics \& Communication University of Allahabad, in 1999 and 2002, respectively, where she is currently pursuing her Ph.D.degree in electronic engineering.

Dr N.K. Shukla is Associate Professor in J.K.Institute of Applied Physics and Technology, University of Allahabad (India). He started teaching in the department as lecturer, having teaching experience of more than 17 Years. His main research area is fiber optics communication and Holography. He has supervised many $\mathrm{PhD}$ candidates. He has published

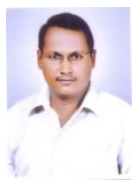
a lot of papers in National, International journals and in National and International conferences. He is a member of many academic bodies of other University and institution, and life member and fellow in organizations like ISTE, IETE etc.

Dr. H.K. Dixit is presently Professor (E\&C) and the former H.O.D J.K. Institute of Applied Physics \&Technology, University of Allahabad (India). He started teaching in the department as lecturer in March 1975 and teaching experience of more than 38 Years. His main research area is fiber optics communication and Holography. He has supervised numerous $\mathrm{PhD}$ candidates and has published a lot of papers in the National, International journals, International conferences. He is also member of RDC, academic bodies of other University, Institution, and life member and fellow in organizations like ISTE, IETE etc. 